\title{
Critically-ill pediatric patients with COVID-19. An update
}

\author{
Pedro Taffarel, M.D. ${ }^{a}$ and Facundo Jorro Barón, M.D. ${ }^{a}$
}

\begin{abstract}
TheCOVID-19 pandemichas grabbed worldwide attention. The different national governments are making an effort to optimize resources and provide effective treatments inasmuch as they are supported by the evidence, at a rate of production in line with the pressing needs. In the field of pediatrics, COVID-19 has a low severity rate compared to the adult population. Approximately $6 \%$ of cases present with a severe course, accounting for patients younger than 1 year and/or with underlying conditions. The therapeutic approach to pediatric patients with COVID-19 is unclear. The small number of pediatric cases hinders the possibility of making evidence-based recommendations for criticallyill patients. The objective of this review is to summarize the different current publications about the clinical course of COVID-19 and its management in critically-ill pediatric patients. Key words: COVID-19, critical disease, pediatrics, SARS-CoV-2, severe acute respiratory syndrome.
\end{abstract}

http: / / dx.doi.org/ 10.5546/ aap.2020.eng.e454

To cite: Taffarel P, Jorro Barón F. Critically-ill pediatric patients with COVID-19. An update. Arch Argent Pediatr 2020;118(5):e454-e462.

\section{INTRODUCTION}

As in the case of any pandemic,

a. Department of Intensive Care of Hospital General de Niños "Dr. Pedro de Elizalde" (HGNPE), Autonomous City of Buenos Aires. Argentina.

E-mail address:

Pedro Taffarel, M.D.: pedrotaffarel@hotmail. com

Funding:

None.

Conflict of interest: None.

Received: 5-8-2020 Accepted: 6-10-2020 date of this article was between $0.1 \%$ and $5.9 \%$ among hospitalized cases. ${ }^{3-9}$ In Argentina, symptoms were mild in $75 \%$ of patients and moderate in $22.1 \%$ (including tachypnea, intercostal retraction, pneumonia, malaise, chest pain, dyspnea, food refusal). Only 3 patients reported severe symptoms; none required mechanical ventilation (MV) and no deaths were registered. ${ }^{10}$ Viral coinfections were also observed in up to two-thirds of cases. ${ }^{11}$

The scarce number of pediatric cases hinders the possibility of making solid, evidence-based recommendations for criticallyill patients; therefore, they are the result of a combination of different bibliographic sources corresponding mostly to adult patients or institutional guidelines / protocols. For example, the recommendations made by the Pediatric Acute Lung Injury Consensus Conference - Paediatric Mechanical Ventilation Consensus Conference (PALICC-PEMVECC). ${ }^{12,13}$ The immediate need to respond to the current pandemic calls for behaviors that take into consideration resource availability, the advent of seasonal epidemics, the risk of staff exposure, adequate treatments, etc.

\section{Clinical presentation and classification of severity}

It is unknown why children are less susceptible to COVID-19 compared to adults. An explanation would be the lower angiotensinconverting enzyme-2 (ACE2) gene expression in the nasal epithelium, which works as a receptor and entry door for SARS-CoV-2. ${ }^{14}$ It has also been suggested that there is an early polyclonal B cell response and a production of substantial amounts 
of plasmablasts, mostly of the IgM isotype. This response has not been observed in adults with a severe course (whose B-cell compartment is depleted). Therefore, a child's immune response may play a double role: to protect and to reduce immune-mediated tissue damage, particularly, in the lung parenchyma. ${ }^{15}$

Dong et al. ${ }^{4}$ defined COVID-19 severity based on clinical characteristics, lab tests, and chest $\mathrm{X}$-ray, and established the following diagnostic criteria:

Asymptomatic disease: no symptom or clinical sign and normal chest X-ray.

Mild disease: symptoms of acute upper respiratory tract infection, including fever, fatigue, myalgia, cough, sore throat, runny nose, and sneezing, in association or not with gastrointestinal symptoms. The physical examination shows pharyngeal congestion.

Moderate disease: pneumonia, fever, and frequent cough (ineffective cough, followed by productive cough), sometimes wheezing, but no clear hypoxemia (peripheral oxygen saturation $\left[\mathrm{SpO}_{2}\right]>92 \%$ ), and auscultatory abnormalities. Some cases may be asymptomatic, but the chest computed tomography (CT) is pathological.

Severe disease: early respiratory symptoms (fever and cough) may be accompanied by gastrointestinal symptoms (diarrhea). The disease progresses over approximately 1 week with dyspnea and central cyanosis. $\mathrm{SpO}_{2}$ is below $92 \%$.

Critical disease: rapid progression to ARDS; patients may also develop shock, encephalopathy, myocardial injury or heart failure, coagulation disorder, and acute kidney injury.

In the past weeks, pediatric patients have presented with a condition similar to toxic shock or Kawasaki disease and a serology that evidenced a potential prior SARS-CoV-2 infection. Tests have shown high white blood cells, platelets, C-reactive protein, and liver enzymes, with no alterations in ferritin, troponin, and D-dimer. ${ }^{16,17}$ A torpid clinical course occurs occasionally with a low fatality rate, as described by the different pediatric series analyzed (Table 1).

When considering only patients admitted to the pediatric intensive care unit (PICU), the mortality rate increases to $5.5 \%$, as observed in the online registers of Virtual PICU Systems, where approximately $30 \%$ of cases are older than 18 years. ${ }^{18}$ Two publications described pediatric patients admitted to the PICU. The patients in the series described by Shekerdemian $(\mathrm{N}=48)$ had a high incidence of preexisting comorbidities $(83 \%)$, with a $4.2 \%$ mortality. In relation to the treatment provided, $38 \%$ of patients required invasive $\mathrm{MV}$, with extracorporeal membrane oxygenation (ECMO) in 1 case; $61 \%$ received targeted therapies, alone or in combination, including hydroxychloroquine (alone or with azithromycin), remdesivir, tocilizumab, and convalescent plasma. ${ }^{8}$ The other series, by González-Dambrauska ${ }^{9}(\mathrm{~N}=17)$, showed that $71 \%$ of cases had a comorbidity, $82 \%$ required ventilatory support, and mortality was $5.9 \%$.

TABLE 1. Seriously-ill patients with COVID-19. Pediatric series

\begin{tabular}{|c|c|c|c|c|c|c|}
\hline \multirow[t]{2}{*}{ Author } & \multirow[t]{2}{*}{ Number of patients } & \multirow{2}{*}{$\begin{array}{c}\text { Serious/critical } \\
\%(\mathbf{N})\end{array}$} & \multicolumn{3}{|c|}{ Ventilatory support } & \multirow{2}{*}{$\begin{array}{l}\text { Death } \\
\%(\mathbf{N})\end{array}$} \\
\hline & & & HFNC & NIV & IMV & \\
\hline Parri et al. ${ }^{3}$ & 67 (hospitalized out of 100 in total) & $4.7(3)$ & 3 & 1 & 1 & $1.5(1)$ \\
\hline Dong et al. ${ }^{4}$ & $\begin{array}{l}731 \text { (confirmed out of } \\
2143 \text { suspected cases) }\end{array}$ & $2.8(21)$ & NS & NS & NS & $0.1(1)$ \\
\hline Lu et al. ${ }^{5}$ & 171 & $1.7(3)$ & NS & NS & 3 & $0.6(1)$ \\
\hline Castagnoli et al. ${ }^{6}$ & 1065 (from 18 studies) & $0.2(2)$ & NS & NS & 1 & $0.1(1)$ \\
\hline CDC COVID-19 & 147 (hospitalized out of 2572 in total) & $10(15)$ & NS & NS & NS & $0.1(3)$ \\
\hline \multicolumn{7}{|l|}{ Response Team ${ }^{7}$} \\
\hline Shekerdemian et al. ${ }^{8}$ & 48 (across 46 PICUs from the USA) & $100(48)$ & 11 & 4 & 18 & $4.2(2)$ \\
\hline $\begin{array}{l}\text { González-Dambrauskas } \\
\text { et al. }{ }^{9}\end{array}$ & $\begin{array}{l}17 \text { (across } 10 \text { PICUs from Chile, } \\
\text { Colombia, Italy, Spain, and USA) }\end{array}$ & $100(17)$ & 7 & 4 & 8 & $5.9(1)$ \\
\hline Total & 2246 & & & & & $0.45(10)$ \\
\hline
\end{tabular}

NS: not specified; HFNC: high-flow nasal cannula; NIV: non-invasive ventilation; IMV: invasive mechanical ventilation; PICUs: pediatric intensive care units. 


\section{Indications for admission to the pediatric intensive care unit}

Patients with severe acute lower respiratory tract infection (ALRTI) or extrapulmonary manifestations associated with severe conditions and / or progressive worsening (Table 2).

\section{Pathophysiological considerations and ventilatory support}

The respiratory condition caused by COVID-19 in the adult population is characterized by marked hypoxemia and relatively adequate respiratory mechanics, with two clinical presentations:

L phenotype: in this presentation, the respiratory system shows a good pulmonary compliance, where lung volume is high, recruitability is minimal, and hypoxemia is the result of the loss of vasomotor tone and reflex vasoconstriction (vasoplegia), with the subsequent alteration of the ventilation/ perfusion ratio $(\mathrm{V} / \mathrm{Q})$.

$\mathrm{H}$ phenotype: it is possibly a progression of the $\mathrm{L}$ type in patients exposed to induced damage (excessive respiratory effort) and behaves more like typical ARDS and shows low pulmonary compliance. ${ }^{19,20}$

According to this interpretation, different recommendations were made based on pathophysiology:

Since invasive MV is not a treatment itself, it should not be started due to hypoxemia alone; an impaired sensorium is the guiding parameter. ${ }^{21}$

TABLE 2. Clinical conditions of critically-ill pediatric patients with COVID-19

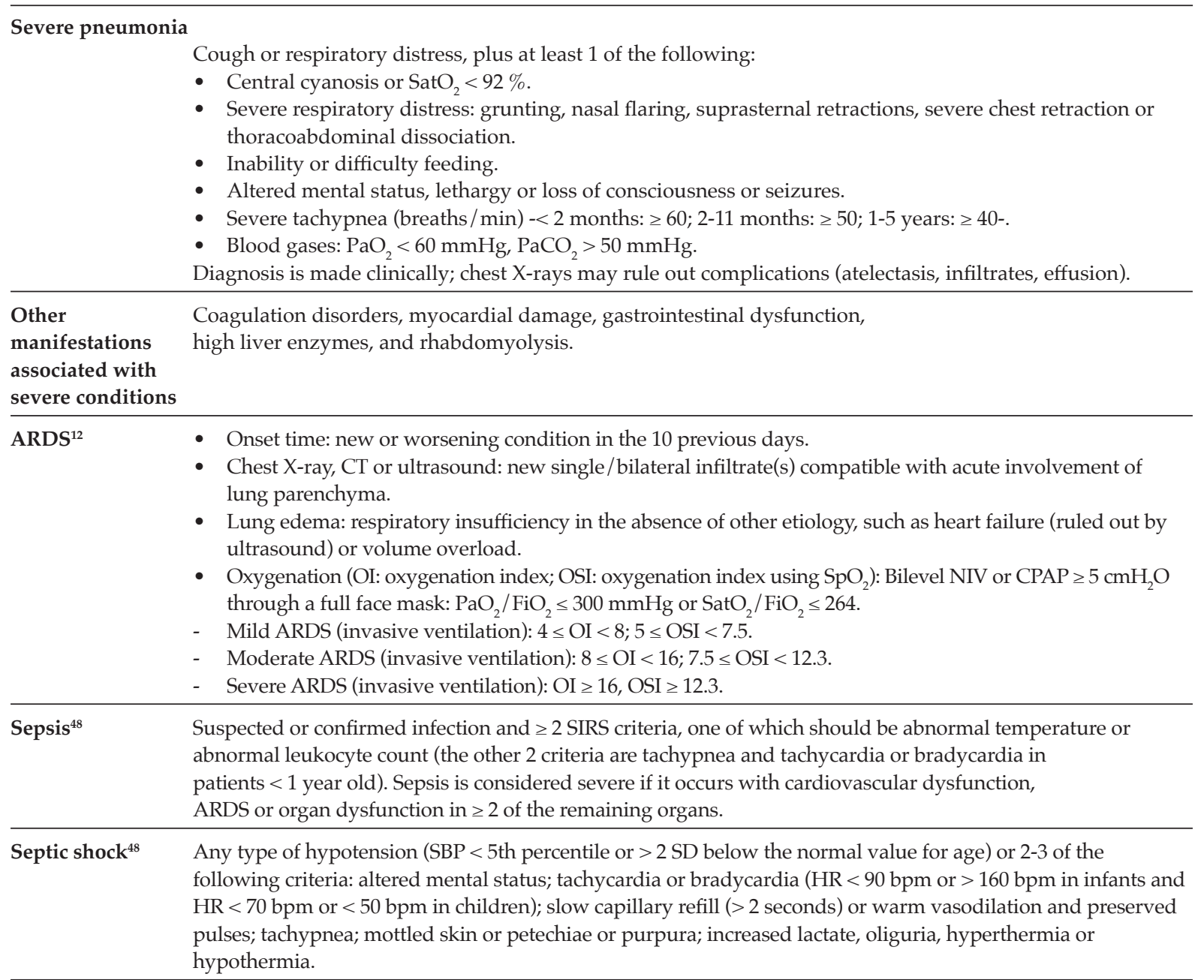

SatO $\mathrm{O}_{2}$ : oxygen saturation; $\mathrm{PaO}_{2}$ : oxygen pressure in arterial blood; $\mathrm{PaCO}_{2}$ : partial pressure of carbon dioxide in arterial blood; ARDS: acute respiratory distress syndrome; $\mathrm{CT}$ : computed tomography; $\mathrm{SpO}_{2}$ : peripheral oxygen saturation; NIV: non-invasive ventilation; CPAP: continuous positive airway pressure; $\mathrm{FiO}_{2}$ : fraction of inspired oxygen; SIRS: systemic inflammatory response syndrome; SBP: systolic blood pressure; SD: standard deviation; HR: heart rate; bpm: beats per minute. 
Since, in the progression of the phenotypes described above, prolonged non-invasive ventilatory support with excessive respiratory effort may be a cause of pulmonary damage, a strict failure criterion should be implemented so that treatment is not extended and invasive support can be initiated. ${ }^{19}$

Once invasive support is started, an attempt should be made to establish the corresponding type of presentation by measuring or estimating pulmonary compliance, which will help to choose the type of ventilatory support. ${ }^{19,10}$

Although it is unknown whether these pathophysiological models can be reproduced in pediatrics, they should be considered during the interpretation of the condition in order to improve how and when to provide ventilatory support.

\section{Non-invasive ventilatory support}

High-flow nasal cannulas (HFNC) and noninvasive ventilation (NIV) have demonstrated to be beneficial in the adult population, ${ }^{22,23}$ although they increase the risk for transmission and infection as a result of high viral particle aerosolization, and may lead to a delay in invasive ventilation. However, these risks should be weighed against the added morbidity resulting from a more aggressive therapy.

The aerosolization caused by HFNC and continuous positive airway pressure (CPAP) will always be limited as long as the patient interface is adequately adjusted. However, exhaled air may leak laterally at more than $60 \mathrm{~cm}$ if the HFNC disengages at the point between the tubing and the patient interface. ${ }^{24}$ In a study conducted in healthy adults, no particle aerosolization between $10 \mathrm{~nm}$ and $500 \mathrm{~nm}$ was observed when using a nasal cannula, a non-rebreather mask or a heated HFNC. ${ }^{25}$

The assessment of response to non-invasive support is based on oxygenation parameters, $\mathrm{SpO}_{2} /$ fraction of inspired oxygen $\left(\mathrm{FiO}_{2}\right)(\mathrm{SF})$ and oxygen saturation index (OSI). The use of CPAP or NIV as first-line method is recommended instead of HFNC in patients with SF $>221$ and $<264 .{ }^{26}$ HFNC with a surgical mask over the patient's face or with a protective acrylic box or other device to minimize aerosol dispersion may be a reasonable practice that would benefit hypoxemic patients with COVID-19 and prevent intubation. ${ }^{27}$

NIV with an oronasal or total face mask interface is recommended to minimize leakage. If possible, use a double-branch circuit (if singlebranch, a filter should be placed before the leakage site -whisper swivel-) and high efficiency particulate air (HEPA) filters in expiratory tubing (both branches if using environmental air). Always humidify the NIV circuit, either actively or passively (heat and moisture exchanger [HME] filter). It is desirable to perform NIV in a negative pressure room; if not possible, in an isolated room or at least with a considerable spatial separation between patients. If oxygenation does

TABLE 3. Endotracheal intubation procedure

Intubation checklist

\section{Plan ahead}

1. Make sure you have practice donning and doffing PPE, and have a partner to check the procedure.

2. Allocate roles: intubator (more experienced in managing airways). Minimize staff inside the room (maximum: 3 people).

3. Negative pressure room, if possible.

4. Establish a clear communication strategy.

\section{Intubation}

1. Don PPE.

2. Determine monitoring, intravenous access, intubation equipment (consider videolaryngoscopy, if available), HME filter between the mask and the bag.

3. Preoxygenate for 3-5 minutes.

4. Plan for RSI induction, minimize self-inflating bag for ventilation.

5. Intubate and confirm (avoid using a stethoscope; use $\mathrm{EtCO}_{2}$ and examination of the chest).

6. Connect to ventilator, with inline suction.

7. Wipe down relevant surfaces.

8. Disposable equipment should be discarded as per the hospital protocol.

9. Ensure proper PPE doffing, monitored by a partner.

PPE: personal protective equipment; $\mathrm{HME}$ : heat and moisture exchanger; $\mathrm{EtCO}_{2}$ : end-tidal $\mathrm{CO}_{2}$; $\mathrm{RSI}$ : rapid sequence intubation. Modified from Paediatric Intensive Care Society UK: Paediatric Critical Care Coronavirus Disease 2019 Guidance.28 
not improve in 30-60 minutes (oxygen saturation $\left[\mathrm{SatO}_{2}\right]$ 92-97\% with $\mathrm{FiO}_{2}<0.4$ ) and respiratory rate/effort does not decrease, treatment escalation to ventilatory support should not be delayed.

\section{Intubation and invasive mechanical ventilation}

Endotracheal intubation should be performed as soon as possible in patients who tend to a worsening SF, progressive respiratory distress, high oxygen levels (>60\%) in HFNC/NIV, altered sensorium or multiple organ failure. An intubation checklist ${ }^{28}$ should be used (Table 3).
During endotracheal intubation, an acrylic box may be used as an extra protection in addition to the standard personal protective equipment (PPE); the box may be dropped if airway management proves difficult. ${ }^{29}$

Ventilation should be done in accordance with the PALICC recommendations ${ }^{12}$ (see algorithm, Figure 1). It is suggested to start with a positive endexpiratory pressure (PEEP) of about $10 \mathrm{cmH}_{2} \mathrm{O}$. PEEP may need to be increased in the case of hypoxemia; high-PEEP strategies are recommended for $\mathrm{FiO}_{2}$; the latter should be titrated to maintain $\mathrm{SpO}_{2}$ at $92-96 \%$ (in the case of severe disease:

FIGURE 1. Invasive ventilatory support algorithm for pediatric patients with COVID-19

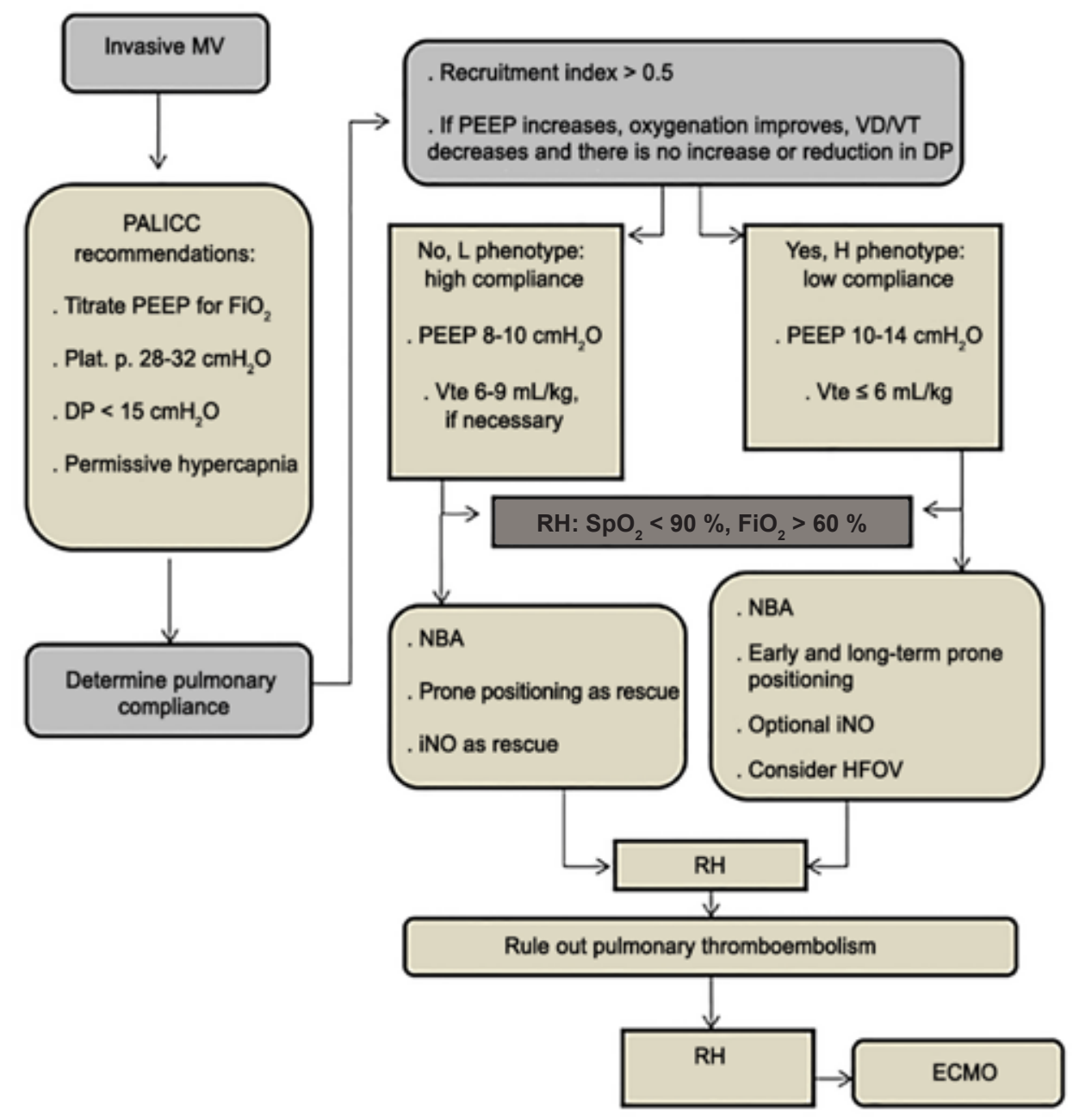

MV: mechanical ventilation; PEEP: positive end-expiratory pressure; Plat. p.: plateau pressure; DP: driving pressure; VD/VT: dead space; Vte: expiratory tidal volume; RH: refractory hypoxemia; iNO: inhaled nitric oxide; NBA: neuromuscular blocking agents; ECMO: extracorporeal membrane oxygenation; HFOV: high frequency oscillatory ventilation.

Source: own creation. 
88-92 \%); and permissive hypercapnia $(\mathrm{pH}>7.20)$ may also be necessary. An early prone positioning (12-18 hours per day) $)^{31}$ and neuromuscular blocking agents (NBA) should be considered for moderatesevere ARDS (oxygen pressure in arterial blood $\left.\left[\mathrm{PaO}_{2}\right] / \mathrm{FiO}_{2}<150\right)$; oxygenation index $(\mathrm{OI}) \geq 12$; OSI $\geq 10$, over $24-48$ hours. Prone positioning should be discontinued when $\mathrm{PaO}_{2} / \mathrm{FiO}_{2}$ is $\geq 150$.

\section{Refractory hypoxemia and management}

If the patient continues with hypoxemia, pulmonary compliance should be determined to establish the ventilation strategy based on the type of clinical presentation, as proposed by Gattinoni. The type of lung (recruitable or not) can be established in different manners. A CT is not an easy option due to the risk for infection and during transfer. A chest X-ray showing hyperinflated lungs and / or a low lung flow is an extreme factor of this outcome measure. A lung ultrasound requires trained staff; pulmonary compliance should be determined using adapted software. However, bedside monitoring and clinical parameters should be available; therefore, PEEP increases in a non-recruitable lung usually lead to a drop in mean blood pressure (MBP) and cardiac output as observed by central venous oxygen saturation $\left(\mathrm{SvO}_{2}\right)$, increased dead space (VD/VT), and increased driving pressure. Another recently disseminated option is the determination of the recruitment index ${ }^{32}$ (see algorithm, Figure 1).

High frequency oscillatory ventilation in the case of refractory hypoxemia and a low pulmonary compliance may also be considered. A bacterial/viral filter system should be added to the circuit's expiratory branch to minimize the risk for aerosol contamination when using leakfree devices (SensorMedics ventilator). ECMO should be considered if refractory hypoxemia persists in spite of the actions implemented, but it should be noted that ECMO is not a firstline therapy to be indicated when all resources become occupied during a pandemic. ${ }^{33}$

In the case of refractory hypoxemia, the following should be considered: presence of pulmonary embolism as confirmed with a chest CT angiography, sequelae of hypercoagulability, endothelial activation at the expense of an increase in proinflammatory cytokines. If this is assumed, it is recommended to measure D-dimer and IL-6 levels and to assess anticoagulation. ${ }^{34,35}$

\section{Precautions for patients with mechanical ventilation}

All staff entering the room of a patient with suspected or confirmed COVID-19 should wear adequate PPE. In parallel, it is recommended to place a filter between the self-inflating bag and the mask or artificial airway. ${ }^{36}$ For patients with an endotracheal tube (ETT), balloon pressure should be maintained between 25 and $30 \mathrm{cmH}_{2} \mathrm{O}$ ( $\left.1 \mathrm{~cm} \mathrm{H}_{2} \mathrm{O}=0.098 \mathrm{kPa}\right)$. It is recommended to minimize ETT disengagement and use closed in-line aspiration, and the device should be changed once a week. Also, it is suggested to use heated, double-branch wire circuits that are only changed in the presence of visible dirt. ${ }^{36}$ Active humidification, with heater and bacterial/viral filters in both ends, may be at risk for aerosol contamination; whereas passive humidification with a HME filter in the distal end has to be changed every 24 hours. ${ }^{26}$ If it is necessary to take the patient off the ventilator, it is recommended to perform a full expiration with the ventilator on stand-by and, if the patient is not receiving NBAs, the ETT should be clamped before disengagement.

In the case of patients who need respiratory support during transfer, the HME filter should be placed between the ventilator and the patient. The secretions resulting from suction should be collected in the same closed containers used during surgical procedures. They have a larger storage capacity and are disposable.

For patients who need aerosol therapy, the recommendation is to use a metered-dose inhaler with spacer if the patient is breathing spontaneously or a vibrating mesh nebulizer if the patient is ventilated. It will be necessary to use an additional filter in the expiratory flow port during nebulization. Routine chest physiotherapy and cough assist devices are not recommended. ${ }^{36}$

\section{Weaning from mechanical ventilation}

The patient should be extubated if they will not require rescue non-invasive support. The recommendation is to perform a spontaneous breathing test with CPAP and/or support pressure not exceeding $5 \mathrm{cmH}_{2} \mathrm{O}$, avoiding the use of a T-piece. When weaning patients who underwent a tracheostomy, HME filters should be used. An unnecessary bronchial hygiene therapy should be avoided. ${ }^{36}$ Precautions to prevent aerosol dispersion are critical during extubation, so an option is to use devices like acrylic boxes, plastic shields, etc. If respiratory effort increases 
following extubation, non-invasive supports may be considered.

\section{Drug treatment ${ }^{26,31,37-40}$}

Corticosteroids: These are not recommended for the management of viral pneumonia outside clinical trials. No benefits have been demonstrated and there may be potential damage related to their use.

Antivirals: There is no current evidence supporting a specific anti-COVID-19 treatment. Available options are derived from the experience of SARS, Middle East respiratory syndrome (MERS), and other influenza virus treatments.

Oseltamivir: It is only considered in the case of influenza co-infection because neuraminidase inhibitors have no effect against COVID-19.

Fabiravir and ribavirin: It has been reported that a combination of fabiravir and oseltamivir for severe flu accelerates recovery, as well as ribavirin and interferon-alpha for SARS, but their benefit in COVID-19 has not been clarified..$^{40}$

Lopinavir/ritonavir: This combination was not effective for COVID-19 in a randomized study in adults with an insufficient sample size. ${ }^{40}$ Some protocols suggested using proteases in children with underlying conditions and immunosuppression of any severity and in critically-ill children admitted to the PICU. If used, this combination is administered in an early manner upon obtaining an informed consent for its compassionate use for 14 days.

Remdesivir: Two adequately designed studies about its use are ongoing. Wang ${ }^{41}$ did not evidence a clinical benefit, although patients receiving remdesivir had a shorter period until clinical improvement than those receiving placebo. The study was discontinued early due to major adverse events in the remdesivir group. Beige et al. ${ }^{42}$ showed that the administration of remdesivir (loading and maintenance dose for 10 days) was associated with fewer days until recovery and a smaller incidence of lower respiratory tract infections in adult patients, without a higher number of adverse events.

Hydroxychloroquine-chloroquine: Both drugs block the membrane receptor ACE2 in SARS-CoV-2. Its use has been proposed for severe cases requiring management at the PICU or for immunocompromised patients with interstitial pneumonia. A recently published multicenter study with these drugs, in association or not with a macrolide, showed a higher rate of in-hospital mortality than in control patients, with a high number of de-novo ventricular arrhythmias. ${ }^{43}$

Intravenous immunoglobulins: These have been used in severe cases, but their indication and effectiveness still need to be assessed. There is currently not enough evidence for their indication. $^{44}$

Convalescent plasma: A pilot study suggested that convalescent plasma administration is safe, reduces viral load, and may improve clinical outcomes. ${ }^{45}$ However, it may only be used as part of a compassionate treatment or in the context of duly regulated clinical trials.

\section{Other support therapies to be considered at the} pediatric intensive care unit

Septic shock: The Surviving Sepsis Campaign (SSC) guidelines for COVID-19 recommend to use a conservative fluid strategy, avoid colloid solutions, and use lowdose corticosteroids for refractory shock to catecholamines. In children, epinephrine is the first-choice vasoactive drug for septic shock. ${ }^{46}$

Co-infections: Secondary bacterial coinfections are common; therefore, a broadspectrum antibiotic therapy should be considered in severe cases.

Myocarditis: A report has been made of a series of 20 pediatric patients with cardiogenic shock and high troponin levels. Treatment included vasoactive support, immunomodulators (methylprednisolone and gamma globulin) and ventilatory support, with a $100 \%$ survival. ${ }^{47}$

\section{COMMENTARY/CONSIDERATION}

The SARS-CoV-2 infection is an emerging pandemic, whose attributable risk and severity among children is currently difficult to establish. The small number of pediatric cases attempts against the recommendations based on strong evidence. The results of international collaborative studies that may improve the classification of clinical presentation, course, and adequate management are now expected.

\section{REFERENCES}

1. Ong JSM, Tosoni A, Kim Y, Kissoon N, et al. Coronavirus Disease 2019 in Critically Ill Children: A Narrative Review of the Literature. Pediatr Crit Care Med.2020 Apr7. [Accessed on: April 20 $\left.{ }^{\text {th }}, 2020\right]$. Available at: http: / / www.ncbi.nlm. nih.gov/pubmed/32265372.

2. Wu Z, McGoogan JM. Characteristics of and Important Lessons from the Coronavirus Disease 2019 (COVID-19) Outbreak in China: Summary of a Report of 72314 Cases from the Chinese Center for Disease Control and Prevention. JAMA. 2020; 323(13):1239-42.

3. Parri N, Lenge M, Buonsenso D. Children with Covid-19 
in Pediatric Emergency Departments in Italy. $\mathrm{N}$ Engl J Med. 2020 May 1. [Accessed on: May 5 ${ }^{\text {th }}, 2020$ ]. Available at: http: / / www.nejm.org/doi/10.1056/ NEJMc2007617.

4. Dong Y,MoX,HuY,QiX,etal.Epidemiologicalcharacteristics of 2143 pediatric patients with 2019 coronavirus disease in China. Pediatrics. 2020. [Accessed on: May $5^{\text {th }}, 2020$ ]. Available at: https:// pediatrics.aappublications.org/ content/ pediatrics / early / 2020/03/16/ peds.2020-0702. full.pdf.

5. Lu X, Zhang L, Du H, Zhang J, et al. SARS-CoV-2 Infection in Children. N Engl J Med. 2020; 382:1663-5.

6. Castagnoli R, Votto M, Licari A, Brambilla I, et al. Severe Acute Respiratory Syndrome Coronavirus 2 (SARS-CoV-2) Infection in Children and Adolescents: a systematic review. JAMA Pediatr. 2020 Apr 22. [Accessed on: May 5 ${ }^{\text {th }}, 2020$ ]. Available at: https:/ / jamanetwork.com/journals / jamapediatrics / fullarticle/ 2765169.

7. Coronavirus Disease 2019 in Children - United States, February 12-April 2, 2020. MMWR Morb Mortal Wkly Rep. 2020; 69(14):422-6.

8. Shekerdemian LS, Mahmood NR, Wolfe KK, Riggs BJ, et al. Characteristics and Outcomes of Children With Coronavirus Disease 2019 (COVID-19) Infection Admitted to US and Canadian Pediatric Intensive Care Units. JAMA Pediatr. 2020 May 11. [Accessed on: May ${ }^{5^{\text {th }}}$,2020]. Available at: https://jamanetwork.com/journals/jamapediatrics / fullarticle/ 2766037.

9. González-Dambrauskas S, Vásquez-Hoyos P, Camporesi A, Díaz-Rubio F, et al. Pediatric critical care and COVID19. Pediatrics. 2020:e20201766.

10. Argentina. Ministerio de Salud. COVID-19. Actualización de la situación epidemiológica en pediatría. [Accessed on: May $\left.5^{\text {th }}, 2020\right]$. Available at: https: / / www.argentina.gob. $\mathrm{ar}$ / sites / default/ files / 20200430-actualización-situacionepidemiológica-covid-19-pediatría.pdf.

11. Cruz AT, Zeichner SL. COVID-19 in Children: Initial Characterization of the Pediatric Disease. Pediatrics. 2020; 145(6):e20200834.

12. Rimensberger PC, Cheifetz IM, Pediatric Acute Lung Injury Consensus Conference Group. Ventilatory support in children with pediatric acute respiratory distress syndrome: Proceedings from the Pediatric Acute Lung Injury Consensus Conference. Pediatr Crit Care Med. 2015; 16(5 Suppl 1):S51-60.

13. Kneyber MCJ, De Luca D, Calderini E, Jarreau PH, et al. Recommendations for mechanical ventilation of critically ill children from the Paediatric Mechanical Ventilation Consensus Conference (PEMVECC). Intensive Care Med. 2017; 43(12):1764-80.

14. Bunyavanich S, Do A, Vicencio A. Nasal Gene Expression of Angiotensin-Converting Enzyme 2 in Children and Adults. JAMA. 2020 May 20. [Accessed on: May $5^{\text {th }}, 2020$ ]. Available at: https: / / jamanetwork.com/journals/jama/ fullarticle/ 2766524.

15. Carsetti R, Quintarelli C, Quinti I, Piano Mortari E, et al. The immune system of children: the key to understanding SARS-CoV-2 susceptibility? Lancet Child Adolesc Health. 2020; 4(6):414-6.

16. PICSUK. *Urgent alert*. Rising no of cases presenting to \#PedsICU with multi-system hyperinflammatory state, overlapping features of toxic shock syndrome \& atypical Kawasaki disease, bloods consistent with severe \#COVID19 - seen in both \#SARSCoV2 PCR +ve AND -ve. Please share widely. Twitter. 2020 Apr 26. [Accessed on: May $\left.8^{\text {th }}, 2020\right]$. Available at: https: / / twitter.com/PICSociety / status/1254508725227982848/photo/1.

17. Verdoni L, Mazza A, Gervasoni A, Martelli L, et al. An outbreak of severe Kawasaki-like disease at the Italian epicentre of the SARS-CoV-2 epidemic: an observational cohort study. Lancet. 2020; 395(10239):1771-8.

18. VPS. COVID-19. Dashboard [Internet]. [Accessed on: May $\left.5^{\text {th }}, 2020\right]$. Available at: https: / / covid19.myvps.org/.

19. Gattinoni L, Chiumello D, Rossi S. COVID-19 pneumonia: ARDS or not? Crit Care. 2020; 24(1):154.

20. Gattinoni L, Chiumello D, Caironi P, Busana M, et al. COVID-19 pneumonia: different respiratory treatment for different phenotypes? Intensive Care Med. 2020 [Accessed on:April 20 $\left.{ }^{\text {th }}, 2020\right]$. Available at: https: / / www.esicm.org/ wp-content/uploads/2020/04/684_author-proof.pdf.

21. Tobin MJ. Basing Respiratory Management of Coronavirus on Physiological Principles. Am J Respir Crit Care Med. 2020 Apr 13. [Accessed on: April 20 ${ }^{\text {th }}, 2020$ ]. Available at: https://www.atsjournals.org/ doi/ full / 10.1164 / rccm.202004-1076ED?url_ver=Z39.882003\&rfr_id=ori \%3Arid \%3Acrossref.org\&rfr_dat $=$ cr_ pub++0pubmed\&.

22. Sun $Q$, Qiu $H$, Huang $M$, Yang $Y$. Lower mortality of COVID-19by early recognition and intervention: experience from Jiangsu Province. Ann Intensive Care. 2020; 10(1):33.

23. Wang K, Zhao W, Li J, Shu W, Duan J. The experience of high-flow nasal cannula in hospitalized patients with 2019 novel coronavirus-infected pneumonia in two hospitals of Chongqing, China. Ann Intensive Care. 2020; 10(1):37.

24. Hui DS, Chow BK, Lo T, Tsang OTY, et al. Exhaled air dispersion during high-flow nasal cannula therapy versus CPAPvia different masks. Eur Respir J. 2019; 53(4):1802339.

25. Iwashyna TJ, Boehman A, Capelcelatro J, Cohn AM, et al. Variation in Aerosol Production Across Oxygen Delivery Devices in Spontaneously Breathing Human Subjects. medRxiv. 2020. [Accessed on: May $7^{\text {th }}, 2020$ ]. Available at: https: / / www.medrxiv.org/ content/10.1101/2020.04.15. 20066688v1.full.pdf.

26. European Society of Paediatric Neonatal Intensive Care. Practice recommendations for managing children with proven or suspected COVID-19. ESPNIC. [Accessed on: April $\left.20^{\text {th }}, 2020\right]$. Available at: https: / / espnic-online.org/News / Latest-News / Practice-recommendations-for-managingchildren-with-proven-or-suspected-COVID-19.

27. Li J, Fink JB, Ehrmann S. High-flow nasal cannula for COVID-19 patients: low risk of bio-aerosol dispersion. Eur Respir J. 2020 Apr 16. [Accessed on: April 20 ${ }^{\text {th }}, 2020$ ]. Available at: http://erj.ersjournals.com/lookup/ doi/10.1183/13993003.00892-2020.

28. UPDATED PICS guidance on covid-19. 14 Mar 2020. Paediatric Intensive Care Society. [Accessed on: April $21^{\text {st, }}$ 2020]. Available at: https://picsociety.uk/news/ updated-pics-guidance-on-covid-19/.

29. Canelli R, Connor CW, Gonzalez M, Nozari A, et al. Barrier Enclosure during Endotracheal Intubation. $N$ Engl J Med. 2020; 382:1957-8

30. Khemani RG, Parvathaneni K, Yehya N, Bhalla AK, et al. Positiveend-expiratory pressure lower than theardsnetwork protocol is associated with higher pediatric acute respiratory distress syndrome mortality. Am J Respir Crit Care Med. 2018; 198(1):77-89.

31. World Health Organization. Clinical management of severe acute respiratory infection when novel coronavirus (nCoV) infection is suspected. Geneva: WHO; 2020. [Accessed on: May $\left.6^{\text {th }}, 2020\right]$. Available at: https:/ / www.who.int/ publications-detail/clinical-management-of-severe-acuterespiratory-infection-when-novel-coronavirus-(ncov)infection-is-suspected.

32. Chen L, Del Sorbo L, Grieco DL, Junhasavasdikul D, et al. Potential for lung recruitment estimated by the recruitmentto-inflation ratio in acute respiratory distress syndrome a clinical trial. Am J Respir Crit Care Med. 2020; 201(2):178-87. 
33. MacLaren G, Fisher D, Brodie D. Preparing for the Most Critically Ill Patients with COVID-19: The Potential Role of Extracorporeal Membrane Oxygenation. JAMA. 2020; 323(13)1245-6.

34. Lang M, Som A, Mendoza DP, Flores EJ, et al. Hypoxaemia related to COVID-19:vascular and perfusion abnormalities on dual-energy CT. Lancet Infect Dis. 2020 [Accessed on: May $\left.5^{\text {th }}, 2020\right]$. Available at: https: / / www.thelancet.com/ pdfs/journals/laninf/PIIS1473-3099(20)30367-4.pdf.

35. Endeman H, Van der Zee P, Van Genderen ME, Van den Akker JPC, et al. Progressive respiratory failure in COVID-19: a hypothesis. Lancet Infect Dis. 2020. [Accessed on: May $\left.5^{\text {th }}, 2020\right]$. Available at: https:/ / www.thelancet. com/journals / laninf/ article / PIIS1473-3099(20)30366-2 / fulltext.

36. Respiratory Care Committee of Chinese Thoracic Society. [ExpertConsensus on Preventing Nosocomial Transmission During Respiratory Care for Critically Ill Patients Infected by 2019 Novel Coronavirus Pneumonia]. Zhonghua Jie He He Hu Xi Za Zhi. 2020;43(4):288-96.

37. Asociación Española dePediatría(AEP), Sociedad Española de Infectología Pediátrica (SEIP), Sociedad Española de Cuidados Intensivos Pediátricos (SECIP). Documento de manejo clinico del paciente pediátrico con infección por SARS-CoV-2. Extracto del Documento de Manejo Clínico del Ministerio de Sanidad. 15 de abril de 2020. [Accessed on: April 20 $\left.0^{\text {th }}, 2020\right]$. Available at: https: / / www.seipweb. es / wp-content / uploads / 2020/04/15_4-AEP-SEIPSECIP-SEUP.-DOCUMENTO-DE-MANEJO-CLINICODEL-PACIENTE-PEDIAi \%CC \%80TRICO-Extracto-deldocumento-del-Ministerio-Propuestas.pdf.

38. Sundaram M, Ravikumar N, Bansal A, Nallasamy K, et al. Novel Coronavirus 2019 (2019-nCoV) Infection: Part II - Respiratory Support in the Pediatric Intensive Care Unit in Resource-limited Settings. Indian Pediatr. 2020;57(4):33542.

39. Ravikumar N, Nallasamy K, Bansal A, Angurana SK, et al. Novel Coronavirus 2019 (2019-nCoV) Infection: Part I Preparedness and Management in the Pediatric Intensive Care Unit in Resource-limited Settings. Indian Pediatr. 2020;
57(4):324-34.

40. Li L, Li R, Wu Z, Yang X, et al. Therapeutic strategies for critically ill patients with COVID-19. Ann Intensive Care. 2020; 10(1)45.

41. Wang Y, Zhang D, Du G, Du R, et al. Remdesivir in adults with severe COVID-19: a randomised, doubleblind, placebo-controlled, multicentre trial. Lancet. 2020; 395(10236):1569-78.

42. Beigel JH, Tomashek KM, Dodd LE, Mehta A, et al. Remdesivir for the treatment of Covid-19 - preliminary report. N Engl J Med. 2020 May. [Accessed on: May 20 $\left.{ }^{\text {th }}, 2020\right]$. Available at: https://www.nejm.org/doi/ full / 10.1056/NEJMoa2007764?url_ver=Z39.88-2003\&rfr_ id=ori:rid:crossref.org\&rfr dat $=$ cr pub $\% 20 \% 200$ pubmed.

43. Mehra MR, Desai SS, Ruschitzka F, Patel AN. Hydroxychloroquine or chloroquine with or without a macrolide for treatment of COVID-19: a multinational registry analysis. Lancet. 2020 May 22. [Accessed on: June $\left.10^{\text {th }}, 2020\right]$. Available at: https://www.thelancet.com/ pdfs/journals/lancet/PIIS0140-6736(20)31180-6.pdf.

44. Cao W, Liu X, Bai T, Fan H, et al. High-Dose Intravenous Immunoglobulin as a Therapeutic Option for Deteriorating Patients With Coronavirus Disease 2019. Open Forum Infect Dis. 2020; 7(3):ofaa102.

45. Shen C, Wang Z, Zhao F, Yang Y, et al. Treatment of 5 Critically Ill Patients With COVID-19 With Convalescent Plasma. JAMA. 2020; 323(16):1582-9.

46. Alhazzani W, Møller MH, Arabi YM, Loeb M, et al. Surviving Sepsis Campaign: guidelines on the management of critically ill adults with Coronavirus Disease 2019 (COVID-19). Intensive Care Med. 2020; 16(5):854-7.

47. Grimaud M, Starck J, Levy M, et al. Acute myocarditis and multisystem inflammatory emerging disease following SARS-CoV-2 infection in critically ill children. Ann Intensive Care. 2020; 10(1):69.

48. Weiss SL, Peters MJ, Alhazzani W, Agus MSD, et al. Surviving sepsis campaign international guidelines for the management of septic shock and sepsis-associated organ dysfunction in children. Intensive Care Med. 2020; 46(Suppl 1):10-67. 